\title{
Obesogenic environments - aspects on measurement and indicators
}

\author{
Liselotte Schäfer Elinder* and Martin Jansson
}

Unit of Applied Nutrition, Stockholm Centre for Public Health, Stockholm County Council, Box 175 33, S-11891 Stockholm, Sweden

Submitted 21 September 2007: Accepted 20 March 2008: First published online 23 May 2008

\begin{abstract}
Background: The focus in understanding the causes of and preventing obesity has broadened from the individual level to include the obesogenic environment. Proving a causal relationship between environmental factors and eating patterns poses a great challenge because randomised controlled trials are seldom possible or feasible to conduct. Interactions between the environment and individuals are beginning to be explored in multilevel studies and qualitative and sociological research.

Aim: The aim is to give an overview of the wider environmental determinants of diet such as the national food supply, food availability and accessibility in different settings as well as the economic food environment and in relation to socio-economic status.

Results: The indicators suggested are based on the amount of data available in the scientific literature and the potential for intervention. They can be used to monitor societal interventions or evaluate 'natural' changes in the food environment. The indicators are of relevance to the Second WHO European Action Plan for Food and Nutrition Policy 2007-2012.

Conclusion: The relatively weak empirical evidence does not imply the absence of causal relationships between environmental factors and diet. Potentially relevant factors have not been evaluated due to the complexity of the task and to lack of political will to change the food environment in a more healthy direction by use of legislation or economic instruments. Future intervention research, targeting the wider environmental determinants of diet, will give us better evidence to propose societal actions to counteract obesity and to strike the right balance between individual and societal action.
\end{abstract}

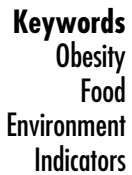

Understanding the determinants of diet and physical activity behaviour and how to measure them are necessary either in intervention studies or in policies aimed at the prevention of obesity. Environmental change is a prime driver of the obesity epidemic, a phenomenon termed the 'obesogenic environment' ${ }^{\text {(1,2) }}$. Worldwide we are experiencing a rise in food availability, food accessibility and sedentariness, which are all factors tightly coupled to overall economic growth and development. More specifically, obesity has been causally linked to the high consumption of soft drinks ${ }^{(3)}$, large portions of energy-dense fast foods ${ }^{(4)}$, skipping breakfast, television viewing, low degree of physical activity and low intake of fruits and vegetables ${ }^{(5,6)}$. These factors are behavioural and can be addressed through health education directed at individuals or groups. Unfortunately, such efforts have not shown much success ${ }^{(7,8)}$, probably because the upstream drivers of obesity are not addressed. Alternatively, a population approach would include environmental change and aim at the creation of environments supporting healthy behaviours. Employing an environmental perspective is, in reality, the most effective way to reach the 'harder to reach' and to deliver sustainable results ${ }^{(2)}$ as experience from, for example, tobacco prevention has shown ${ }^{(9)}$.

In the early 1990s, studies in the UK and the USA began to show associations between area of residence and health behaviour ${ }^{(10-12)}$, as well as body size and shape after controlling for individual characteristics such as gender, age, social class, smoking behaviour and material deprivation $^{(13,14)}$. The differences in health behaviour between various residential areas could be linked to local opportunities for healthy eating and physical activity, suggesting that obese persons may be exposed to environments predisposing them to the risk of obesity to a higher degree than normal-weight persons. However, the evidence of area differences has not been consistent, and the direction of causality is impossible to define from cross-sectional studies. This raised the question as to whether local variations in obesity prevalence depend on the place (physical environment or material factors, also 
termed context) rather than on the characteristics of individuals (age, gender, income and education, ethnicity, also termed composition) ${ }^{(15)}$. In other words, can geographic variation in area obesogenicity explain neighbourhood differences in obesity or do different groups in society react differently to the same obesogenic environment?

Today, there is an overwhelming body of literature showing that the main divider of diet, physical activity and obesity is social class, which is commonly characterised by income, type of employment and education $^{(16-23)}$, thus encompassing a number of specific social, psychological and material exposures that influence health ${ }^{(15)}$. However, because changes in the environment are fundamental drivers of the obesity epidemic, and because environmental factors are probably easier targets for change than income and education, defining the role of the environment and its interaction with socioeconomic status seems nevertheless important.

The aim of the present paper is to give a selective rather than an exhaustive overview of the literature on some of the most studied characteristics of the obesogenic environment with a focus on diet and on indicators to measure and evaluate it. It will also be discussed how these factors interact with social class. These factors mainly relate to the specific actions of the Second WHO European Action Plan for Food and Nutrition Policy 2007-2012 ${ }^{(24)}$ called Ensuring a safe, bealthy and sustainable food supply (action area 2). Interactions between the environment and other moderating factors such as age, gender and ethnicity, although significant, will not be discussed due to limitation of space. This overview is based on the causal web for obesity developed by the International Obesity Task Force (IOTF) ${ }^{(25)}$, showing the factors that operate at different structural levels from the global to the individual level. This web represents an ecological framework of health.

\section{The search for environmental determinants of diet}

The limited success of health education approaches with regard to the primary prevention of chronic diseases has intensified the search for 'upstream' or wider environmental determinants of diet and obesity ${ }^{(26-28)}$. By environment we here mean all factors external to a person while environmental determinants of health refer to those external factors and conditions that influence health ${ }^{(29)}$ (see Table 1).

However, establishing causal relationships between environmental factors and population diet poses a great challenge due to a number of reasons. First, there is, at present, no 'gold standard' for measuring material resources like, for example, access to food, while it is even harder to measure the social environment such as parental or peer influence and how they affect the development of social norms. Therefore, the development and validation of methods on how to assess environmental influences should be strengthened. Second, causality gets harder to prove, the further upstream we go in the health determinant chain. Randomisation and control become increasingly difficult because the number of units decreases. The importance of upstream factors such as the agreement on world food trade can only be evaluated through health impact assessment ${ }^{(30)}$ or simulation models of scenarios. Both methods rely heavily on assumptions and are inherently uncertain. Third, dynamic interactions within and between individual and societal levels complicate the

Table 1 Summary table of potential environmental determinants of diet and suggested indicators

\begin{tabular}{|c|c|c|}
\hline Environmental determinant & Indicator & Source of information \\
\hline National food supply & Per capita food availability & National bureaus of statistics, FAOSTAT-Nutrition \\
\hline \multirow[t]{3}{*}{ Local environment } & Food access radar & National Consumer Council $(2006)^{(51)}$ \\
\hline & $\begin{array}{l}\text { Availability, price and quality of indicator } \\
\text { foods (NEMS-S) }\end{array}$ & Glanz et al. $(2007)^{(53)}$ \\
\hline & Healthy eating indicator shopping basket tool (HEISB) & Anderson et al. (2007) \\
\hline \multirow[t]{2}{*}{ Restaurants and catering } & Nutrition quality of meals (NEMS-R) & Saelens et al. $(2007)^{(58)}$ \\
\hline & Share of meals with a defined health symbol & von Haartman $(2006)^{(63)}$ \\
\hline \multirow[t]{3}{*}{ Schools } & $\begin{array}{l}\text { Presence of school fruit and vegetable programmes } \\
\text { (free or subsidised) }\end{array}$ & Lock and de Sa $(2008)^{(76)}$; Bere et al. $(2007)^{(72)}$ \\
\hline & $\begin{array}{l}\text { Share of schools with a ban on the sale of soft drinks } \\
\text { and candy }\end{array}$ & von Haartman $(2006)^{(63)}$ \\
\hline & $\begin{array}{l}\text { Presence of nutrition guidelines for school meals } \\
\text { (free or subsidised) and share of schools complying } \\
\text { with guidelines }\end{array}$ & Donnelly et al. (1996) ${ }^{(69)}$; Luepker et al. $(1996)^{(70)}$ \\
\hline Work place & $\begin{array}{l}\text { Presence of staff canteens serving quality meals rich } \\
\text { in fruits and vegetables }\end{array}$ & Roos et al. (2004) ${ }^{(74)}$; Lassen et al. $(2004)^{(75)}$ \\
\hline \multirow[t]{2}{*}{ Home environment } & Availability of fruit and vegetables & Rasmussen et al. $(2006)^{(67)}$ \\
\hline & $\begin{array}{l}\text { Share of family meals consisting of low-quality } \\
\text { convenience foods and take-away }\end{array}$ & Inglis et al. (2005) ${ }^{(43)}$; van der Horst et al. $(2007)^{(77)}$ \\
\hline \multirow[t]{2}{*}{ Price } & $\begin{array}{l}\text { Cost per unit of energy of chosen indicator foods } \\
\text { and time trends }\end{array}$ & $\begin{array}{l}\text { Drewnowski and Darmon (2005) })^{(83)} \text {; Drewnowski } \\
\text { et al. }(2007)^{(87)}\end{array}$ \\
\hline & $\begin{array}{l}\text { Presence and magnitude of food taxes and } \\
\text { subsidies at state level or in specific settings }\end{array}$ & $\begin{array}{l}\text { Jensen and Smed }(2007)^{(86)} ; \text { French }(2003)^{(88)} \\
\quad \text { Horgen and Brownell }(2002)^{(89)}\end{array}$ \\
\hline
\end{tabular}


interpretation of results ${ }^{(15)}$. Multilevel studies are beginning to be performed, addressing both individual-level determinants and area characteristics. But these studies can only suggest causality, not prove it. Unmeasured or unknown individual effects, such as religious belief, can be misinterpreted as a contextual (environmental) effect. Proof of causality between area effects, behaviour and health outcomes can only be established through controlled and randomised intervention trials, which are almost unthinkable when it comes to wider environmental factors. Therefore, the best evidence possible on environmental determinants of diet is evaluations of 'natural experiments' or quasi-experimental intervention trials. Results obtained in quantitative studies have to be verified through sociological research and qualitative studies exploring people's own views and experiences on their opportunities and barriers to healthy eating. In order to perform these studies, we need reliable indicators of environmental determinants.

\section{Suggested indicators for environmental determinants of diet}

Indicators are measures for latent variables like, for example, quality of school meals or affordability of healthy foods. The indicators suggested are based on the amount of data available in the scientific literature and the potential for intervention. The overview is mainly concerned with macro-scale factors according to the IOTF causal web ${ }^{(25)}$.

\section{Food supply}

At the macro-level, food supply is a primary determinant of the diet of the population. In Europe and other regions of the world, food energy availability has been continuously increasing and in Europe food security has been ensured since the late $1960 \mathrm{~s}^{(31)}$. The European Union Common Agricultural policy, which is regulating the food supply in Europe through economic incentives in combination with border protection, has been shaping diets in Europe through decades with both positive and negative public health impacts ${ }^{(32)}$. Today, food patterns in Europe are converging with those of the Northern European countries, resulting in an increased intake of animal fat and a lower intake of fruits and vegetables ${ }^{(33)}$. This development is of concern especially to Mediterranean countries, which have traditionally had more healthful diets ${ }^{(34)}$.

A good example of how rapid yet unintentional changes in the food supply can affect diets for the better is Poland. Due to political and economic transformations that began in the late 1980s, general purchasing power fell, and the withdrawal of large consumer subsidies, especially for butter and lard, led to a sharp reduction in sales in these foods. As a consequence, a new market for vegetable fat producers suddenly emerged. The resulting fall in saturated fat intake was associated with a rapid decrease in cardiovascular mortality in Poland. Mortality trends have continued to fall and were $38 \%$ lower among middle-aged men in 2002 compared to 1990, and were $42 \%$ lower among middle-aged women. The main reason is believed to be a $70 \%$ lower ratio of saturated to unsaturated fat in the Polish $\operatorname{diet}^{(35)}$. Therefore, food balance sheets are important ecological measures of trends in the national per capita food availability although they overestimate actual consumption by individuals because they include spoilage and waste. Food balance sheets are available nationally or from the FAO, which among many other variables provides statistics on commodities, food supply and food balance sheets (FAOSTAT-Nutrition). An example of the type of information that can be obtained from food balance sheets is statistics released from the Swedish Board of Agriculture. These data show that during the period 1980-2005, the daily supply of food energy increased from 12 to about $12.5 \mathrm{MJ}$ per capita. The total consumption of flour and grain increased by $11 \%$, meat by $28 \%$, vegetables by $74 \%$ and fruit by $20 \%$. The total consumption of milk during the same period decreased by $24 \%$. Also the consumption of edible fats decreased during the period by $33 \%$.

\section{Access to neighbourbood food shops}

Food retailing has undergone a revolution since the 1960s driven both by supply and by demand ${ }^{(36)}$. For decades we have experience falling food prices, except for a very recent rise, and massively increased access to foods and ready-made meals. A major trend is the decline of smaller shops in town centres and a corresponding rise in large out-of-town supermarkets. In the beginning of the $1990 \mathrm{~s}$ this led to worries, mainly in the UK, that 'urban food deserts' may increase the inequality in health because healthy food had become more expensive and less available in poorer areas. A cross-sectional study from the USA showed a $35 \%$ higher risk of obesity in areas with access to only grocery and/or convenience stores but no supermarkets ${ }^{(14)}$. The association was attenuated if adjusting for individual gender, age, income and education but, according to the authors, the findings were compatible with a causal effect of the local food environment on diet and obesity. Other studies from the USA have demonstrated that people on low income and blacks have poorer access to healthier foods and better access to unhealthy food ${ }^{(37-39)}$ and that this is associated with unhealthier eating patterns and obesity ${ }^{(12)}$. A strong association between neighbourhood deprivation and geographic access to fast-food outlets has also been found in New Zealand ${ }^{(40)}$.

Findings from the $\mathrm{UK}^{(41)}$, the Netherlands ${ }^{(41,42)}$ and Australia ${ }^{(43-45)}$ have not confirmed this picture. In a crosssectional study from Newcastle, UK, the authors were unable to demonstrate that food availability, proximity or 
price was statistically associated with individual dietary pattern $^{(36)}$. The factors that predicted healthiness of diet were dietary knowledge, a healthy lifestyle in general, age, sex, ethnicity and socio-economic status. In two intervention studies from the UK, attempts were made to increase fruit and vegetable intake through the establishment of supermarkets in deprived communities, which resulted in a modest but positive impact on the consumption of fruit and vegetable consumption ${ }^{(46)}$. Together, this led the British researchers to the conclusion that food retail access in urban areas per se does not have a profound or prolonged effect on dietary patterns ${ }^{(47)}$. One explanation for the lack of association between food retail distribution and diet could be that low-income consumers demonstrate a sophisticated strategy for economic shopping also outside of their local neighbourhood ${ }^{(36)}$. Thus, the measurement at this local scale might have been too static and does not take into account the real-world 'actionspaces' of individuals, a problem described as 'falling into the local trap, ${ }^{,(4)}$. This problem could also explain the contrasting results found between countries.

Qualitative studies from both the $\mathrm{UK}^{(49)}$ and Australia ${ }^{(45)}$ indicate that personal factors present bigger barriers to healthy eating than access and price. Concerning youth from low-income families, Evans et al. have documented that healthful eating is important to this population, but perceived external barriers prevent the consistent consumption of healthful foods ${ }^{(50)}$, emphasising a role of the environment.

A number of refined tools have been developed recently, allowing more detailed studies of the association between food environments and eating behaviour. In the UK, the National Consumer Council released a tool called the Food Access Radar to be used by researchers as well as local planners ${ }^{(51)}$. The Food Access Radar measures physical access to food shops, it uses census data and geographic information systems technology to identify where socio-economic and sociodemographic factors create barriers to healthy eating. The radar can be combined with shop visits in order to map the cost and availability of specific foods and food quality. An initiative from Scotland is the development of a healthy eating indicator shopping basket tool (HEISB) for use in access studies $^{(52)}$. This tool comprises 35 items from six food categories and is based on nutrient profiling developed by the UK Food Standards Agency. It provides a standardised tool for examining the price and availability of a wider range of healthy foods. Glanz et al. have developed a similar nutrition environment measure (NEMS-S) instrument to assess the community nutrition environment within retail food stores, including aspects such as availability, price and quality of indicator foods ${ }^{(53)}$. Indicator foods were selected on the basis of guidelines and recommendations. The tool shows a high reliability, good face validity and can be tailored to the needs of specific studies. A drawback of all these food availability tools is that they are labour-intensive. However, these tools could be of help in future observational and intervention studies on the effect of food availability and access on dietary patterns. Such tools are also useful in assessing the commitments made by various commercial stakeholders in the fight against obesity.

\section{Access to restaurants and catering}

A high intake of energy-dense fast food is associated with a higher energy and fat intake in adolescents ${ }^{(54)}$ and adults $^{(55)}$ as well as weight gain and insulin resistance ${ }^{(4)}$. The frequency of fast-food restaurant use was higher among younger women, those with lower income and non-white ethnicity. Qualitative studies based on interviews with different socio-economic status (SES) groups from Australia have reported that low-SES groups express concern about the number of fast-food outlets available in their local neighbourhood and found this setting to be deterrent to healthy eating ${ }^{(43)}$. The access to fast-food outlets serving energy-dense and large-portion meals in deprived areas has also been identified as being a potential contributor to obesity by lowering the dietary quality, thus resulting in an increase in the prevalence of obesity in both the USA ${ }^{(56-60)}$ and Europe ${ }^{(57)}$. But the results have been contradictory ${ }^{(61,62)}$ and observational studies cannot define the direction of causality. There is a limitation in using restaurant proximity and density as a proxy for individuals' food environment because restaurants vary widely in meal availability, price, quality and the way meals are served and promoted. In order to address this complexity, Saelens et al. ${ }^{(58)}$ have developed an evaluation instrument called nutrition environment measures study in restaurants (NEMS-R) capable of discriminating restaurant types and the way restaurants discourage healthy eating through availability, signage and price. This instrument showed good reliability. However, it was not designed to directly measure portion size. When it comes to establishing associations between eating patterns and health outcomes, the limitation of this instrument as well as those designed to evaluate the effects of retailing on food purchase is that people move out of their local areas to shop and dine. Therefore, ideally such studies should be accompanied by quantitative data on people's movements in everyday life.

The 'share of keyhole-labelled meals' has been suggested as an indicator of the food environment in Sweden within the catering services and restaurants ${ }^{(63)}$. The green 'keyhole' is a health symbol developed by the Swedish Food Administration used on a voluntary basis on food packages and menus with a healthier nutrition profile ${ }^{(64)}$. It is meant to give consumers an easy choice within categories. For foods and menus to be eligible for labelling with the keyhole symbol, they must meet certain criteria on the amounts of total fat, saturated and trans fat, dietary fibre, sugars and salt ${ }^{(65)}$. At present, conditions have been specified for twenty-six food groups that can 
be labelled with the keyhole symbol as well as on menus and recipes for restaurants and fast-food outlets. The advantage of this indicator is that it is considerably easier to use than, for example, the NEMS-R tool would be. Other countries like Finland have developed their own symbol in the form of a red heart, which is used in the same way.

\section{Food access in schools and workplaces}

The food environment in schools and workplaces can have significant effects on food choice ${ }^{(66)}$. Students who participate in school lunch programmes have a higher and more frequent intake of fruits and vegetables than students who do not participate ${ }^{(67)}$. Many countries have nutrition guidelines for school meals. Although it is difficult to prove that guidelines in themselves lead to overall better dietary habits among schoolchildren, it is recommended that improved school meals should be part of a whole-school approach to obesity prevention ${ }^{(68)}$. Furthermore, changes to school lunch programmes have resulted in significant improvements in diet and eating behaviour ${ }^{(69,70)}$.

If high-fat snacks are offered and sold to students at school through vending machines or cafeterias, they will displace fruits and vegetables ${ }^{(67,71)}$. Conversely, results from the Norwegian school fruit scheme have shown that provision of daily school fruit can lower the consumption of 'junk food' and have sustained effects after 3 years ${ }^{(72)}$. In Finland, authorities were able to dramatically increase the consumption of fruits and vegetables through the introduction of a regulation that required all meals provided by public food service outlets to be served with vegetables or salad ${ }^{(73)}$. Roos et al. from Finland could demonstrate that having lunch at a staff canteen is associated with recommended food habits and a higher vegetable intake ${ }^{(74)}$. In Denmark, a work-site canteen study was very successful in increasing the intake of fruits and vegetables in both blue and white collar workplaces ${ }^{(75)}$.

A recent systematic review of the effectiveness of interventions to promote fruit and/or vegetable consumption in children in schools worldwide showed that school-based schemes are effective at increasing both intake of, and positive knowledge and attitudes to fruit and vegetable intake $^{(76)}$. Of the 35 studies included, $65 \%$ of studies in both younger and older age groups showed statistically significant increases in fruit and vegetable intake at followup, with none decreasing intake. Twenty-five studies had follow-up periods greater than 1 year and this review provides evidence that both large (national)- and smaller (local)-scale fruit and vegetable schemes can have longterm impacts on consumption. Only one study showed an effect on both increasing fruit and vegetable intake and decreasing overweight in the same study, which would be expected to occur at longer time scales that change in dietary intake.

Based on this research, several countries are now discussing new approaches either to limit the availability of 'junk food' in schools and/or to increase the availability of healthy food. In 2005, local authorities in Brussels banned vending machines in all of the city's primary schools. In Germany, local officials have banned kiosks from selling candy and sodas near schools; in France, vending machines in schools have been banned since 2005; and in Sweden many schools and municipalities prohibit the sale of candy and soft drinks on school premises. The signalling impact on children and parents of such initiatives to modulate the food environment could turn out to be just as important as the restriction itself.

On the basis of these studies, potential indicators of the school and workplace food environment could be the 'presence of school fruit and vegetable schemes' - whether they are free or subsidised - and the 'presence of regulations concerning junk food and sweetened beverages'. A recent investigation into food accessibility and nutrition in Sweden ${ }^{(63)}$ suggested to use the indicator 'share of schools with a ban on the sale of soft drinks and candy'.

\section{Access to food at bome}

For fruit and vegetable consumption among children and adolescents, gender, age, socio-economic position, preferences, parental intake and home availability/accessibility are the determinants supported by the greatest amount of evidence ${ }^{(67)}$. Availability at home is particularly important to address because it influences intake even when preferences are low.

In a recent systematic review of environmental correlates of obesity-related dietary behaviours in youth, van der Horst et al. ${ }^{(77)}$ concluded that parental dietary intakes, sibling intakes and educational level of parents were factors most consistently associated with children's diets. Another review ${ }^{(67)}$ underlines the lack of studies regarding children and the role of environmental factors at higher levels such as neighbourhoods and municipalities, let alone national-level factors.

Qualitative studies on social class differences in food consumption have shown that middle-class mothers consider health more frequently as a primary concern, whereas low-class mothers mention the cost of food and family preferences as important in their choice of food ${ }^{(23)}$. Furthermore, low-class women were more permissive toward food choices of their children. An Australian study showed similar differences and that lower-class women more often reported time constraints due to work and therefore preferred convenience foods and take-away, which often has a higher energy content and lower nutrient quality ${ }^{(43)}$.

Relevant indicators of home support to healthy eating could be the availability of fruits and vegetables as well as the share of family meals consisting of low-quality convenience foods and take-away.

\section{Price of food}

Pricing strategies have the potential to be a broad-based and effective method for intervention with regard to changing the eating behaviour of the population ${ }^{(78,79)}$. 
However, the empirical evidence that economic instruments will work as an anti-obesity strategy is still weak ${ }^{(80)}$. Even though the price of food is lower than ever before in history - constituting on average 13\% of household budgets in Europe $^{(81)}$ - food price is an important determinant of food selection, especially among low-income groups ${ }^{(43,82,83)}$. Studies from the USA suggest that in areas served by smaller grocery stores, usually found in low-income neighbourhoods, the access to healthier food products is limited and a healthy food basket is also more expensive ${ }^{(84)}$. However, area-based studies in the UK and France have shown that while healthier food baskets cost more than unhealthy ones, both healthy and unhealthy foods tend to be cheaper in low-income $\operatorname{areas}^{(36)}$.

Price elasticity of food measures the responsiveness of the quantity demanded to a unit change in price. The price elasticity of various foods decreases with income, which means that as consumers get richer they respond less to price changes of food ${ }^{(85)}$, which has implications for social inequalities in food consumption. At income levels found in Europe and the USA, food is said to be relatively inelastic (elasticity between -1 and +1 ) compared to other consumables like recreation, transport and medical care. For example, soft drinks have a price elasticity of around -0.7 and fruits and vegetables between -0.6 and $-0.9^{(86)}$, the same elasticity range as tobacco and wine.

Drewnowski and Darmon argue that the link between poverty and obesity is primarily accounted for by the higher energy cost of healthy relative to unhealthy foods ${ }^{(83)}$. They found an inverse relationship between energy density of foods and their energy cost, with fruits and vegetables being 100-fold more expensive per unit of energy compared to fats and sugar. Therefore, energydense diets based on refined grains, added sugars and added fats are more affordable per unit of energy than the recommended diets based on lean meats, fish, fresh fruits and vegetables. Based on French data, Drewnowski and Darmon found that diets in the highest quintile of energy density high in fat were more than $25 \%$ cheaper than those of the lowest energy density, which were also rich in vitamin $C$, folate and fibre ${ }^{(87)}$. An indicator that could be used to measure the economic food environment is the price per unit of energy of foods from different groups such as fats/oils, sugars, meat, fish, dairy and fruits and vegetables, and the price development over time. Analysis of time trends has revealed that the price of fruits and vegetables has increased threefold more than that of fats and sugars over the last two decades ${ }^{(83)}$. Thus, according to this hypothesis, relative food prices might explain why poorer people have less healthy diets. Economic regulation of food prices through taxes and subsidies represents a cost-effective option to provide consumers with economic incentives to change their eating patterns in a healthier direction ${ }^{(86)}$ and should be tested on a large scale. Presence of taxes and subsidies on foods and beverages could be another indicator of the economic food environment.

Within closed systems, such as canteens in workplaces or schools, it has been shown that elaborating with the price of different food items can directly affect purchase patterns ${ }^{(88)}$. When the price of low-fat items in vending machines was reduced by $10-50 \%$, the proportion of low-fat snacks purchased increased by 9-93\%. Halving the price on fruits and baby carrots in a high school cafeteria increased sales by a factor of 2-4. It was concluded that price reductions are an effective strategy to increase the purchase of more healthful foods in settings such as work sites and schools. A similar finding was reported from a restaurant setting where a 4-month price reduction of $20-30 \%$ on healthy food items, such as sandwiches, salads and soups, led to higher sales ${ }^{(89)}$. Price reduction was more effective than health messages.

\section{Obesogenic environments - for whom?}

Not everybody is obese in spite of the fact that we all live in obesogenic environments. A decreasing share of the population is resilient, defined as a 'dynamic process encompassing positive adaptation within the context of significant adversity ${ }^{(90)}$. Ana Diez Roux concluded from her studies on health that 'person is more important than place $^{,(91)}$. However, even if individual choice is ultimately more important than the environment, there is obviously a problem with the 'place' if an increasing number of people fail to keep a healthy body weight. In order to establish associations between the obesogenic environment, eating patterns and health, we need good and reliable tools and indicators to characterise these environments. In order to prove causality we need good intervention studies or evaluations of 'natural experiments' and tools to monitor changes. Findings in quantitative studies need to be verified through qualitative research exploring people's own views and experiences on their opportunities and barriers to a healthy lifestyle. A useful theory to understand how behaviours are shaped as an interaction between individuals and their environment is social cognitive theory, emphasising the reciprocal relationship between people and their environment ${ }^{(92)}$.

Unfortunately, the driving forces for environmental research and action are weak, and the counter forces from commercial stakeholders are strong. The relatively weak evidence found must not be interpreted as the absence of causal relationships, because many potentially relevant environmental factors, particularly at the macrolevel, have not been studied due to the complexity of the task $^{(93)}$ and to lack of political will to change the food environment in a more healthy direction by use of legislation or economic instruments. The environmental factors suggested in the present paper concerning food supply, access to and price of food, if targeted in future 
intervention research, will give us better evidence to propose societal actions to counteract obesity and to strike the right balance between individual and societal action in order to stop current obesity trends. The intention of the Second WHO European Action Plan for Food and Nutrition Policy 2007-2012 ${ }^{(24)}$ signed by all fifty-three European member states is to redirect the focus of action in creating healthy food environments from the individual towards the responsibility of governments and corporations.

\section{Acknowledgements}

Funding source: The first author is a temporary adviser to WHO, who funded the work.

Conflict of interest: The authors have no conflict of interest.

Author contributions: L.S.E. was the primary writer of the paper. M.J. contributed the sociological perspective.

Acknowledgements: We thank the WHO Regional Office for Europe's nutrition team for their valuable comments to the manuscript. We also thank the anonymous reviewers for their constructive comments.

\section{References}

1. Swinburn B, Egger G \& Raza F (1999) Dissecting obesogenic environments: the development and application of a framework for identifying and prioritizing environmental interventions for obesity. Prev Med 29, 563-570.

2. Swinburn B \& Egger G (2002) Preventive strategies against weight gain and obesity. Obes Rev 3, 289-301.

3. Malik VS, Schulze MB \& Hu FB (2006) Intake of sugarsweetened beverages and weight gain: a systematic review. Am J Clin Nutr 84, 274-288.

4. Pereira MA, Kartashov AI, Ebbeling CB, Slattery ML, Jacobs DR \& Ludwig DS (2005) Fast-food habits, weight gain, and insulin resistance (the CARDIA study): 15-year prospective analysis. Lancet 365, 36-42.

5. Ball K, Salmon J, Giles-Corti B \& Crawford D (2006) How can socio-economic differences in physical activity among women be explained? A qualitative study. Women Health 43, 93-113.

6. Kumanyika SK (2001) Minisymposium on obesity: overview and some strategic considerations. Annu Rev Public Health 22, 293-308.

7. Brown T, Kelly S \& Summerbell C (2007) Prevention of obesity: a review of interventions. Obes Rev 8, Suppl. 1, 127-130.

8. Summerbell CD, Waters E, Edmunds LD, Kelly S, Brown T \& Campbell KJ (2005) Interventions for preventing obesity in children. Cochrane Database Syst Rev issue 3, CD001871.

9. West R (2007) What lessons can be learned from tobacco control for combating the growing prevalence of obesity? Obes Rev 8, Suppl. 1, 145-150.

10. Diehr P, Koepsell T, Cheadle A, Psaty BM, Wagner E \& Curry S (1993) Do communities differ in health behaviors? J Clin Epidemiol 46, 1141-1149.

11. Ellaway A \& Macintyre S (1996) Does where you live predict health related behaviours? A case study in Glasgow. Health Bull (Edinb) 54, 443-446.

12. Morland K, Wing S, Diez Roux A \& Poole C (2002) Neighborhood characteristics associated with the location of food stores and food service places. Am J Prev Med $\mathbf{2 2}$, 23-29.

13. Ellaway A, Anderson A \& Macintyre S (1997) Does area of residence affect body size and shape? Int J Obes Relat Metab Disord 21, 304-308.

14. Morland K, Diez Roux AV \& Wing S (2006) Supermarkets, other food stores, and obesity: the atherosclerosis risk in communities study. Am J Prev Med 30, 333-339.

15. Macintyre S, Ellaway A \& Cummins S (2002) Place effects on health: how can we conceptualise, operationalise and measure them? Soc Sci Med 55, 125-139.

16. Ball K \& Crawford D (2005) Socioeconomic status and weight change in adults: a review. Soc Sci Med 60, 1987-2010.

17. James WP, Nelson M, Ralph A \& Leather S (1997) Socioeconomic determinants of health. The contribution of nutrition to inequalities in health. BMJ 314, 1545-1549.

18. Giles-Corti B \& Donovan RJ (2002) Socioeconomic status differences in recreational physical activity levels and real and perceived access to a supportive physical environment. Prev Med 35, 601-611.

19. Giskes K, Turrell G, Patterson C \& Newman B (2002) Socioeconomic differences in fruit and vegetable consumption among Australian adolescents and adults. Public Health Nutr 5, 663-669.

20. Giskes K, Turrell G, Patterson C \& Newman B (2002) Socioeconomic differences among Australian adults in consumption of fruit and vegetables and intakes of vitamins A, C and folate. J Hum Nutr Diet 15, 375-385; discussion 387-390.

21. Groth MV, Fagt S \& Brondsted L (2001) Social determinants of dietary habits in Denmark. Eur J Clin Nutr 55, 959-966.

22. Dowler E (2001) Inequalities in diet and physical activity in Europe. Public Health Nutr 4, 701-709.

23. Hupkens CL, Knibbe RA \& Drop MJ (2000) Social class differences in food consumption. Eur J Public Health 10, 108-113.

24. World Health Organization (2007) Second WHO European Action Plan for Food and Nutrition Policy 2007-2012. Copenhagen: WHO Regional Office for Europe.

25. International Association for the Study of Obesity (1999) The causal web. http://www.iaso.org/newsletter/ p10spring99.htm

26. Booth SL, Sallis JF, Ritenbaugh C et al. (2001) Environmental and societal factors affect food choice and physical activity: rationale, influences, and leverage points. Nutr Rev 59, S21-S39; discussion S57-65.

27. Richter KP, Harris KJ, Paine-Andrews A, Fawcett SB, Schmid TL, Lankenau BH \& Johnston J (2000) Measuring the health environment for physical activity and nutrition among youth: a review for physical activity and applications for community initiatives. Prev Med 31, 98-111.

28. Ferreira I, van der Horst K, Wendel-Vos W, Kremers S, van Lenthe FJ \& Brug J (2007) Environmental correlates of physical activity in youth - a review and update. Obes Rev $\mathbf{8}, 129-154$.

29. Green LW \& Kreuter MW (2005) Health Program Planning. An Educational and Ecological Approach. New York: McGraw-Hill Companies.

30. Scott-Samuel A \& O'Keefe E (2007) Health impact assessment, human rights and global public policy: a critical appraisal. Bull World Health Organ 85, 212-217.

31. United Nations Food and Agriculture Organization (2002) World Agriculture: Towards 2015/2030, Summary Report. Rome: FAO

32. Elinder LS (2005) Obesity, hunger, and agriculture: the damaging role of subsidies. BMJ 331, 1333-1336.

33. Balanza R, Garcia-Lorda P, Perez-Rodrigo C, Aranceta J, Bonet MB \& Salas-Salvado J (2007) Trends in food availability determined by the Food and Agriculture 
Organization's food balance sheets in Mediterranean Europe in comparison with other European areas. Public Health Nutr 10, 168-176.

34. Trichopoulou A, Costacou T, Bamia C \& Trichopoulos D (2003) Adherence to a Mediterranean diet and survival in a Greek population. $N$ Engl J Med 348, 2599-2608.

35. Zatonski W \& Willett W (2005) Changes in dietary fat and declining coronary heart disease in Poland: population based study. BMJ 331, 187-188.

36. White M (2007) Food access and obesity. Obes Rev $\mathbf{8}$, Suppl. 1, 99-107.

37. Moore LV \& Diez Roux AV (2006) Associations of neighborhood characteristics with the location and type of food stores. Am J Public Health 96, 325-331.

38. Galvez MP, Morland K, Raines C, Kobil J, Siskind J, Godbold J \& Brenner B (2007) Race and food store availability in an inner-city neighbourhood. Public Health Nutr (Epublication ahead of print version).

39. Morland K \& Filomena S (2007) Disparities in the availability of fruits and vegetables between racially segregated urban neighbourhoods. Public Health Nutr 10, 1481-1489.

40. Pearce J, Blakely T, Witten K \& Bartie P (2007) Neighborhood deprivation and access to fast-food retailing: a national study. Am J Prev Med 32, 375-382.

41. Pearson T, Russell J, Campbell MJ \& Barker ME (2005) Do 'food deserts' influence fruit and vegetable consumption? A cross-sectional study. Appetite 45, 195-197.

42. Cummins S, Petticrew M, Higgins C, Findlay A \& Sparks L (2005) Large scale food retailing as an intervention for diet and health: quasi-experimental evaluation of a natural experiment. I Epidemiol Community Health 59, $1035-1040$.

43. Inglis V, Ball K \& Crawford D (2005) Why do women of low socioeconomic status have poorer dietary behaviours than women of higher socioeconomic status? A qualitative exploration. Appetite 45, 334-343.

44. Turrell G, Blakely T, Patterson C \& Oldenburg B (2004) A multilevel analysis of socioeconomic (small area) differences in household food purchasing behaviour. $J$ Epidemiol Community Health 58, 208-215.

45. Ball K, Crawford D \& Mishra G (2006) Socio-economic inequalities in women's fruit and vegetable intakes: a multilevel study of individual, social and environmental mediators. Public Health Nutr 9, 623-630.

46. Wrigley N, Warm D \& Margetts B (2003) Deprivation, diet, and food-retail access: findings from the Leeds 'food deserts' study. Environ Plann 35, 151-188.

47. Cummins S \& Macintyre S (2006) Food environments and obesity - neighbourhood or nation? Int J Epidemiol 35, 100-104.

48. Cummins S (2007) Commentary: Investigating neighbourhood effects on health - avoiding the 'local trap'. Int $J$ Epidemiol 36, 355-357.

49. Dibsdall LA, Lambert N, Bobbin RF \& Frewer LJ (2003) Low-income consumers' attitudes and behaviour towards access, availability and motivation to eat fruit and vegetables. Public Health Nutr 6, 159-168.

50. Evans AE, Wilson DK, Buck J, Torbett H \& Williams J (2006) Outcome expectations, barriers, and strategies for healthful eating: a perspective from adolescents from low-income families. Fam Community Health 29, 17-27.

51. National Consumer Council (2006) Food Access Radar. A Step by Step Guide. London: National Consumer Council.

52. Anderson A, Dewar J, Marshall D, Cummins S, Taylor M, Dawson J \& Sparks L (2007) The development of a healthy eating indicator shopping basket tool (HEISB) for use in food access studies - identification of key food items. Public Health Nutr 10, 1440-1447.
53. Glanz K, Sallis JF, Saelens BE \& Frank LD (2007) Nutrition Environment Measures Survey in stores (NEMS-S): development and evaluation. Am J Prev Med 32, 282-289.

54. French SA, Story M, Neumark-Sztainer D, Fulkerson JA \& Hannan P (2001) Fast food restaurant use among adolescents: associations with nutrient intake, food choices and behavioral and psychosocial variables. Int $J$ Obes Relat Metab Disord 25, 1823-1833.

55. French SA, Harnack L \& Jeffery RW (2000) Fast food restaurant use among women in the Pound of Prevention study: dietary, behavioral and demographic correlates. Int J Obes Relat Metab Disord 24, 1353-1359.

56. Maddock J (2004) The relationship between obesity and the prevalence of fast food restaurants: state-level analysis. Am J Health Promot 19, 137-143.

57. Cummins SC, McKay L \& MacIntyre S (2005) McDonald's restaurants and neighborhood deprivation in Scotland and England. Am J Prev Med 29, 308-310.

58. Saelens BE, Glanz K, Sallis JF \& Frank LD (2007) Nutrition Environment Measures Study in restaurants (NEMS-R): development and evaluation. Am J Prev Med 32, 273-281.

59. Block JP, Scribner RA \& DeSalvo KB (2004) Fast food, race/ ethnicity, and income: a geographic analysis. Am J Prev Med 27, 211-217.

60. Maddock J (2004) The relationship between obesity and the prevalence of fast food restaurants: state-level analysis. Am J Health Promot 19, 137-143.

61. Macintyre S, McKay L, Cummins S \& Burns C (2005) Outof-home food outlets and area deprivation: case study in Glasgow, UK. Int J Behav Nutr Phys Act 2, 16.

62. Cummins S (2007) Neighbourhood food environment and diet: time for improved conceptual models? Prev Med 44, 196-197.

63. von Haartman F (2006) Livsmedelstillgänglighet i Sverige indikatorer och metoder för kartläggning (Food accessibility in Sweden - indicators and methods for mapping). Stockholm: Statens folkhälsoinstitut.

64. Bohman U \& Laser Reuterswärd A (2006) Förslag till framtidens nyckelhålsmärkning $i$ storbushåll - certifieringssystem och nya kriterier (Proposal for a future key bole labelling in catering services - certification and new criteria). Uppsala: The National Food Administration.

65. National Food Administration (2008) Rules for the Keybole Symbol. Uppsala: National Food Administration.

66. French SA (2005) Public strategies for dietary change: schools and worksites. J Nutr 135, 910-912.

67. Rasmussen M, Krolner R, Klepp KI, Lytle L, Brug J, Bere E \& Due P (2006) Determinants of fruit and vegetable consumption among children and adolescents: a review of the literature. Part I: quantitative studies. Int J Behav Nutr Phys Act 3, 22.

68. Micucci S, Thomas H \& Vohra J (2002) The Effectiveness of School-based Strategies for the Primary Prevention of Obesity and for Promoting Physical Activity and/or Nutrition, the Major Modifiable Risk Factors for Type 2 Diabetes: a Review of Reviews. Hamilton, Ontario: City of Hamilton.

69. Donnelly JE, Jacobsen DJ, Whatley JE, Hill JO, Swift LL, Cherrington A, Polk B, Tran ZV \& Reed G (1996) Nutrition and physical activity program to attenuate obesity and promote physical and metabolic fitness in elementary school children. Obes Res 4 , 229-243.

70. Luepker RV, Perry CL, McKinlay SM et al. (1996) Outcomes of a field trial to improve children's dietary patterns and physical activity. The Child and Adolescent Trial for Cardiovascular Health. CATCH collaborative group. JAMA 275, 768-776.

71. Kubik MY, Lytle LA, Hannan PJ, Perry CL \& Story M (2003) The association of the school food environment with dietary behaviors of young adoescents. Am J Public Health 93, 1168-1173. 
72. Bere E, Veierod MB, Skare O \& Klepp KI (2007) Free school fruit - sustained effect three years later. Int J Behav Nutr Phys Act 4, 5.

73. Puska P (2002) Successful prevention of non-communicable diseases: 25 year experiences with North Karelia project in Finland. Public Health Med 4, 5-7.

74. Roos E, Sarlio-Lahteenkorva S \& Lallukka T (2004) Having lunch at a staff canteen is associated with recommended food habits. Public Health Nutr 7, 53-61.

75. Lassen A, Thorsen AV, Trolle E, Elsig M \& Ovesen L (2004) Successful strategies to increase the consumption of fruits and vegetables: results from the Danish ' 6 a day' Work-site Canteen Model Study. Public Health Nutr 7, 263-270.

76. Lock K \& de Sa J (2008) Effectiveness of School Fruit and Vegetable Schemes. London: London School of Hygiene and Tropical Medicine.

77. van der Horst K, Oenema A, Ferreira I, Wendel-Vos W, Giskes K, van Lenthe F \& Brug J (2007) A systematic review of environmental correlates of obesity-related dietary behaviors in youth. Health Educ Res 22, 203-226.

78. French SA, Story M \& Jeffery RW (2001) Environmental influences on eating and physical activity. Annu Rev Public Health 22, 309-335.

79. Danish Academy of Technical Sciences (2008) Economic Nutrition Policy Tools - Useful in the Challenge to Combat Obesity and Poor Nutrition? Copenhagen: Danish Academy of Technical Sciences.

80. Goodman C \& Anise A (2006) What is Known About the Effectiveness of Economic Instruments to Reduce Consumption of Foods High in Saturated Fats and Other Energy-dense Foods for Preventing and Treating Obesity? Copenhagen: WHO Regional Office for Europe (Health Evidence Network report).

81. Organisation for Economic Co-operation and Development (2004) Changing Food Lifestyles: Emerging Consumer Concerns. Paris: OECD.

82. Lennernäs M, Fjellström C, Becker W, Giachetti I, Schmitt A, Remaut de Winter AM \& Kearney M (1997) Influences on food choice perceived to be important by nationally-representative samples of adults in the European Union. Eur J Clin Nutr 51, Suppl. 2, 8-15.

83. Drewnowski A \& Darmon N (2005) The economics of obesity: dietary energy density and energy cost. Am J Clin Nutr 82, Suppl., 265S-273S.

84. Jetter KM \& Cassady DL (2006) The availability and cost of healthier food alternatives. Am J Prev Med 30, 38-44.

85. Regmi A, Deepak M, Seale JL \& Bernstein J (2001) Crosscountry analysis of food consumption patterns. In Changing Structure of Global Food Consumption and Trade, pp. 14-22 [A Regmi, editor]. Washington DC: Economic Research Service, US Department of Agriculture.

86. Jensen JD \& Smed S (2007) Cost-effective design of economic instruments in nutrition policy. Int J Behav Nutr Phys Act 4, 10.

87. Drewnowski A, Monsivais P, Maillot M \& Darmon N (2007) Low-energy-density diets are associated with higher diet quality and higher diet costs in French adults. J Am Diet Assoc 107, 1028-1032.

88. French SA (2003) Pricing effects on food choices. J Nutr 133, 841S-843S.

89. Horgen KB \& Brownell KD (2002) Comparison of price change and health message interventions in promoting healthy food choices. Health Psychol 21, 505-512.

90. Ball K \& Crawford D (2006) Socio-economic factors in obesity: a case of slim chance in a fat world? Asia Pac J Clin Nutr 15, Suppl., 15-20.

91. Diez Roux AV (2002) Invited commentary: places, people, and health. Am J Epidemiol 155, 516-519.

92. Baranowski T, Perry CL \& Parcel GS (2002) How individuals, environments, and health behavoir interact: social cognitive theory. In Health Behaviour and Health Education. Theory, Research, and Practice, pp. 165-184 [K Glanz, BK Rimer, FM Lewis, editors]. San Francisco, CA: Jossey-Bass.

93. Brug J, van Lenthe FJ \& Kremers SP (2006) Revisiting Kurt Lewin how to gain insight into environmental correlates of obesogenic behaviors. Am J Prev Med 31, $525-529$. 